\title{
Decreased cell stiffness facilitates cell detachment and cell migration from breast cancer spheroids in 3D collagen matrices of different rigidity
}

Ghodeejah Higgins ${ }^{1}$, Jessica E Kim ${ }^{2}$, Jacopo Ferruzzi ${ }^{2}$, Tamer Abdalrahman ${ }^{1}$, Thomas Franz $^{1,3^{*}}$, Muhammad H Zaman ${ }^{2,4^{*}}$

${ }^{1}$ Division of Biomedical Engineering, Department of Human Biology, University of Cape Town, Observatory, South Africa

${ }^{2}$ Department of Biomedical Engineering, Boston University, Boston, MA, USA

${ }^{3}$ Bioengineering Science Research Group, Engineering Sciences, University of Southampton, Greenfield, UK

${ }^{4}$ Howard Hughes Medical Institute, Chevy Chase, MD, USA

\section{ORCID}

G Higgins: 0000-0003-3576-9031

JE Kim: 0000-0003-0090-5603

J Ferruzzi:

T Abdalrahman: 0000-0002-0320-811X

T Franz: 0000-0002-1504-3842

MH Zaman: 0000-0002-3723-5431

*Joint corresponding authors:

Thomas Franz: thomas.franz@uct.ac.za

Muhammad H Zaman: zaman@bu.edu 


\begin{abstract}
Purpose: Tumour-cell detachment is a critical early event in the metastatic cascade. Although several mechanisms have been reported, the role of cell mechanical properties in facilitating cell detachment and migration is not well understood. We, therefore, investigated how cells alter intracellular stiffness during these processes.

Methods: MDA-MB-231 cells were embedded as 10,000-cell spheroids in 2 and $4 \mathrm{mg} / \mathrm{ml}$ collagen matrices. Using mitochondrial-based particle tracking microrheology (PTM), the intracellular stiffness of cells that have migrated different distances from the spheroid were assessed. Here, $0 \mathrm{~d}_{\mathrm{C}}, 4 \mathrm{~d}_{\mathrm{C}}$ and $6 \mathrm{~d}_{\mathrm{C}}$ represented no, medium and high migration, respectively.

Results: For 2 and $4 \mathrm{mg} / \mathrm{ml}$ collagen matrices, the MSD and cell stiffness of Odc cells were larger than for migrated $4 d_{c}$ and $6 d_{c}$ cells. The MSD of $4 d_{c}$ and $6 d_{c}$ cells were similar; however, the cell stiffness of $4 \mathrm{dc}$ cells was smaller than that of $6 \mathrm{dc}_{\mathrm{c}}$ cells. The stiffness of $0 \mathrm{dc}$ cells was lower for higher matrix concentration and rigidity compared to lower matrix rigidity, whereas matrix rigidity did not affect the stiffness of $4 d_{C}$ and $6 d_{C}$ cells.

Conclusions: PTM was capable of quantifying intracellular mechanics during tumour detachment and migration in 3D environments. Based on our findings, it is proposed that decreased cell stiffness drives cellular detachment and migration. Increased matrix rigidity physically hinders migration and cells need to either soften or remodel the environment to migrate. The finding that matrix rigidity did not affect the stiffness of migrated cells suggests that cells facilitate migration by remodelling their environment through cleavage of matrix proteins.
\end{abstract}

Keywords: Breast cancer spheroids, Cell detachment, Cell migration, Cell stiffness; Mitochondrial-based particle tracking microrheology, 3D matrix rigidity

Funding: This study was supported financially by the National Research Foundation of South Africa (grant number IFR14011761118 to TF), the South African Medical Research Council (grant number SIR328148 to TF) and the National Institutes of Health [grant numbers U01CA202123 and P01HL120839 to MHZ]. This research was also supported in part by the National Institutes of Health training grant at Boston University, T32 EB006359 that supported the work of JEK. GH acknowledges a Max \& Lillie Sonnenberg International Travel Scholarship of the University of Cape Town. Any opinion, findings and conclusions or recommendations expressed in this publication are those of the authors and do not necessarily represent the official views of the funding agencies. 
Conflicts of interest: The authors declare that they do not have conflicts of interest.

Ethics approval: Not applicable

Consent to participate: Not applicable

Consent for publication: Not applicable

Availability of data and material: Data presented in this article are available on ZivaHub under http://doi.org/10.25375/uct.13359398.

Code availability: Not applicable

\section{Authors' contributions:}

- G Higgins: Conceptualization, Data Curation, Formal analysis, Investigation, Methodology, Project administration, Software, Visualization, Writing - Original Draft, Writing - Review \& Editing.

- J Kim: Conceptualization, Investigation, Methodology, Project administration.

- J Ferruzzi: Conceptualization, Methodology.

- T Abdalrahman: Formal analysis, Software.

- T Franz: Funding acquisition, Resources, Supervision, Writing - Review \& Editing.

- MH Zaman: Conceptualization, Methodology, Resources, Formal analysis, Supervision, Writing - Review \& Editing. 


\section{Introduction}

Metastatic cancer cells alternate between various labour-intensive tasks associated with disease progression, including detachment from the tumour, invasion into the tumour environment and formation of new tumours (Gal and Weihs 2012). Considerable attention has focussed on understanding the role that the mechanical properties of cancer cells play in these processes. It has been shown that the mechanical properties have crucial implications in regulating chemical and mechanical cues and in maintaining cell or tissue architecture in several cell types, including metastatic cancerous cells (Cui et al. 2017, Mak et al. 2014).

Many of these studies have probed cells in two-dimensional environments. However, cells in two-dimensional (2D) and three-dimensional (3D) environments exhibit substantial differences in morphology, gene expression, and mechanical and structural properties. Several studies reported a marked decrease in intracellular fluctuations from 2D to 3D environments (Baker et al. 2009, Mak et al. 2014). Additionally, 3D in vitro systems can recapitulate in vivo conditions more closely than 2D systems (Baker et al. 2009).

Studies of solid tumours should, therefore, incorporate 3D models that mimic complex tumour architecture, including cell-cell and cell-matrix interactions (Close et al. 2018). Cell spheroids are powerful in mimicking many aspects of solid tumours, including architecture (i.e. an outer proliferative layer of cells, a middle layer of senescent cells and a core of necrotic cells), enhanced cell-cell and cell-matrix connections, and gene expression (Costa et al. 2016, Fennema et al. 2013).

Tumour spheroid assays have addressed essential questions relating to spheroid morphology, growth, viability, drug development (Close et al. 2018), signalling pathways associated with cell detachment and invasion (Naber et al. 2012), cancer stem cell content (Reynolds et al. 2017). However, only few studies have investigated cell mechanics in the detachment and invasion process - owing to technical challenges of quantifying the mechanics of live cells in 3D environments during detachment and invasion. Microrheology can offer non-invasive techniques that allow passively probing intra-cellular mechanics to characterise single cell and collective cell behaviour without introducing cellular and matrix deformation (Mak et al. 2014).

It is generally accepted that elevated tissue rigidity is a characteristic of solid tumours (Wullkopf et al. 2018) and that cells adapt their stiffness to the environmental stiffness (Mitrossilis et al. 2010). It is of interest to investigate whether and how cells adapt their 
stiffness during tumour detachment and invasion as the disease progresses. It has been shown that reduced cell-cell adhesion decreases cell stiffness (Omidvar et al. 2014) and increases migration (Geiger et al. 2019) and that increased migration and decreased cell stiffness are directly correlated (Guck et al. 2005, Remmerbach et al. 2009). However, it is not yet known whether these observations of cellular mechanics translate directly to physiologically relevant environments that mimic the tumour-cell detachment process. Considering that the mechanical properties of cells depend on the properties of the extracellular matrix (ECM), it is essential to clarify how cells regulate their mechanical properties when the properties of the ECM change. This study aimed to determine the intracellular stiffness of metastatic breast cancer cells during tumour detachment and invasion by combining a 3D spheroid model and mitochondrial particle tracking microrheology (PTM). Different levels of migratory capacity were established by considering cells increasingly migratory with increasing migration distance from the spheroid.

\section{Materials and methods}

\subsection{Cell culture}

Metastatic breast adenocarcinoma cells, MDA-MB-231, were cultured in DMEM (Dulbecco's Modified Eagle Medium, Life Technologies), supplemented with $10 \%$ foetal bovine serum (FBS) and $1 \%$ penicillin-streptomycin, and maintained in $25 \mathrm{~cm}^{2}$ tissue flasks (Costar, Corning Life Science, Acton, MA) at $37^{\circ} \mathrm{C}$ and $5 \% \mathrm{CO}_{2}$ until near-confluency. Media was replaced every 3-4 days. Cells were used in passages 6-16.

\subsection{Spheroid formation}

To form spheroids, cell suspensions were grown in agarose-coated well plates according to the liquid overlay method (Metzger et al. 2011). An agarose solution was prepared by diluting 0.18 g agarose (Sigma-Aldrich, St. Louis, MO) in $12 \mathrm{ml}$ 1XPBS and heated in a microwave oven for $36 \mathrm{~s}$ or until the agarose dissolved. The solution was immediately transferred to sterile conditions and kept on a hot plate to prevent premature gelation. A 96-well plate was prepared by pipetting $70 \mu \mathrm{l}$ of the hot liquid agarose solution onto the flat bottoms of the wells, ensuring the solution covered the entire surface and contained no air bubbles. The agarose-coated 96well plate was exposed to ultraviolet light for 30 minutes for sterilisation. Separately, cell monolayers were lifted from the culture flask using standard laboratory trypsinisation procedures. Spheroids of 10,000 cells were created by placing $100 \mu l$ trypsinised cells $(100,000$ 
cells $/ \mathrm{ml}$ containing $2.5 \%$ Matrigel) into the agarose-coated wells, centrifuged at 1,000 rpm for 5 mins, and incubated at $37^{\circ} \mathrm{C}$ and $5 \% \mathrm{CO}_{2}$ for $72 \mathrm{hrs}$.

\subsection{Spheroid collagen embedding}

MDA-MB-231 spheroids were embedded in Type I Rat Tail Collagen Solutions (BD Biosciences) at final collagen concentrations of 2 and $4 \mathrm{mg} / \mathrm{ml}$. Type I Rat Tail Collagen at a stock solution of $9.61 \mathrm{mg} / \mathrm{ml}$ was combined with equal amounts of neutralising solution (100 mM HEPES in 2X PBS with pH 7.3), and further diluted with 1XPBS on ice to create 2 and 4 $\mathrm{mg} / \mathrm{ml}$ collagen solutions. Spheroids were added to the unpolymerised collagen solutions on $35 \mathrm{~mm}$ glass-bottom dishes, with each $50 \mu \mathrm{l}$ collagen solution containing one spheroid to avoid spheroid-spheroid interaction, and incubated at $37^{\circ} \mathrm{C}$ and $5 \% \mathrm{CO}_{2}$ for $1 \mathrm{hr}$. After $1 \mathrm{hr}$, the collagen solutions polymerised and $500 \mu 1$ media were added.

\subsection{Mitochondrial particle tracking microrheology}

Embedded MDA-MB-231 tumour spheroids were prepared for mitochondrial tracking by adding $500 \mathrm{nM}$ Mitotracker Red solution (Life Technologies, Carlsbad, CA) to the supplemented DMEM media 24 hrs before experimentation to allow the Mitotracker solution to sufficiently diffuse through the spheroid. Before imaging, the media was removed from the wells and the wells placed in an environmental chamber at $37^{\circ} \mathrm{C}$ and $5 \% \mathrm{CO}_{2}$.

After 24 hrs, cells started detaching from the spheroid and migrating into the collagen gel predominantly as linear branches with a leader cell and follower cells.

To avoid boundary effects of the rigid 2D glass-bottom surface and to ensure full engulfment, cell branches near the middle of the collagen gel were located and imaged. Mitochondrial fluctuations of branching cells at the spheroid surface and varying distances from the spheroid were captured using time-lapse fluorescent imaging for $120 \mathrm{~s}$ (exposure time: $50 \mathrm{~ms} / \mathrm{frame}$; spinning disk confocal microscope, $63 \times 1.4$ oil immersion objective and CCD camera, Hamamatsu Photonics, Hamamatsu, Japan). Fluorescent images were acquired of surface and migrated cells (branched). The distance migrated $\left(\mathrm{d}_{\mathrm{m}}\right)$ from the spheroid was reported in terms of cell diameter $\left(\mathrm{d}_{\mathrm{C}}\right)$, where $\mathrm{d}_{\mathrm{m}}=0 \mathrm{~d}_{\mathrm{C}}, 4 \mathrm{~d}_{\mathrm{C}}$ and $6 \mathrm{~d}_{\mathrm{C}}$ correspond to the cell at the spheroid surface, intermediately migrated, and furthest migrated, respectively. These experiments were repeated on two independent days $(\mathrm{n}=2)$, with data taken from at least two spheroids, each with at least five branches comprising at least six migrated cells.

Post-processing involved constructing mitochondrial trajectories using TrackMate (Tinevez et al. 2017) in Fiji Image $\mathbf{J}$ (Schindelin et al. 2012). The tracking assumed particles with a 
diameter of $1 \mu \mathrm{m}$ and allowed up to 4 missed frames between subsequent spots to account for missing detections. Mitochondrial trajectories were imported into MATLAB (The MathWorks, Natick, MA), and the ensemble-averaged, time-dependent mean square displacement (MSD) was calculated using @msdanalyzer (Tarantino et al. 2014) according to:

$$
\left\langle\Delta r^{2}(\tau)_{x y}\right\rangle=\langle[x(t+\tau)-x(t)]+[y(t+\tau)-y(t)]\rangle^{2}
$$

Here, $\left\langle\Delta \mathrm{r}^{2}(\tau)_{x y}\right\rangle$ is the ensemble-averaged MSD, $\tau$ is the time interval or delay time between the first and last image frame used for the analysis, and $x(t)$ and $y(t)$ refer to the spatial coordinates of particle positions at time $t$.

The MSD increases with delay time according to a power-law relationship, $\left\langle\Delta \mathrm{r}^{2}(\tau)\right\rangle \sim \tau^{\alpha}($ Baker et al. 2010). The MSD-dependent power-law coefficient or diffusivity coefficient $\alpha=\partial \ln \left\langle\Delta \mathrm{r}^{2}\right.$ $(\tau)\rangle / \partial \ln (\tau)$ represents the intracellular fluidity (deformability).

\subsection{Statistical analysis}

Data are reported as mean \pm standard deviation in the text. Error bars in graphs represent the standard error of the mean (SEM). Two-way ANOVA was employed to detect differences in MSD and fluidity of cells at different delay times. ANOVA assessed two main effects, i.e. distance from the spheroid and changes in collagen concentration, and one interaction between main effects. The migrated distance contained three levels, i.e. no migration, medium migration, and large migration, with which posthoc analysis was performed using Tukey's HSD test. The collagen concentration contained two levels, i.e. $2 \mathrm{mg} / \mathrm{ml}$ and $4 \mathrm{mg} / \mathrm{ml} \mathrm{collagen}$, and ANOVA was followed up with linearly independent pairwise comparisons among estimated marginal means.

A criterion for statistical significance of $p<.05$ formed the basis of all evaluations. SPSS Statistics for Windows (Version 25.0, IBM Corp., Armonk, NY) was used for all statistical analyses.

\section{Results}

To provide a platform for cell detachment from tumours and migration in physiologically relevant environments, metastatic breast cancer cells (MDA-MB-231) were embedded as tumour spheroids in 3D collagen matrices. Mitochondrial PTM experiments $(n=2)$ were conducted after $24 \mathrm{hrs}$ of incubation when cells started detaching from spheroids. 
The use of mitochondria as tracer particles to determine the viscoelastic response of cells has been validated; Mak et al. (2014) showed that the MSD of mitochondria and ballistically injected nanoparticles was similar when used in metastatic breast cancer MDA-MB-231 cells (Mak et al. 2014). For short delay times, the mitochondrial MSD primarily represents the viscoelastic properties of a cell, whereas active motor-driven cellular processes dominate the MSD for long delay times (Kim et al. 2018, Mak et al. 2014).

Following detachment from the tumour surface, cells invaded the tumour environment predominantly in linear branches. In these branches, several cells trailed a leader cell and migrated away from the tumour (Figure 1).

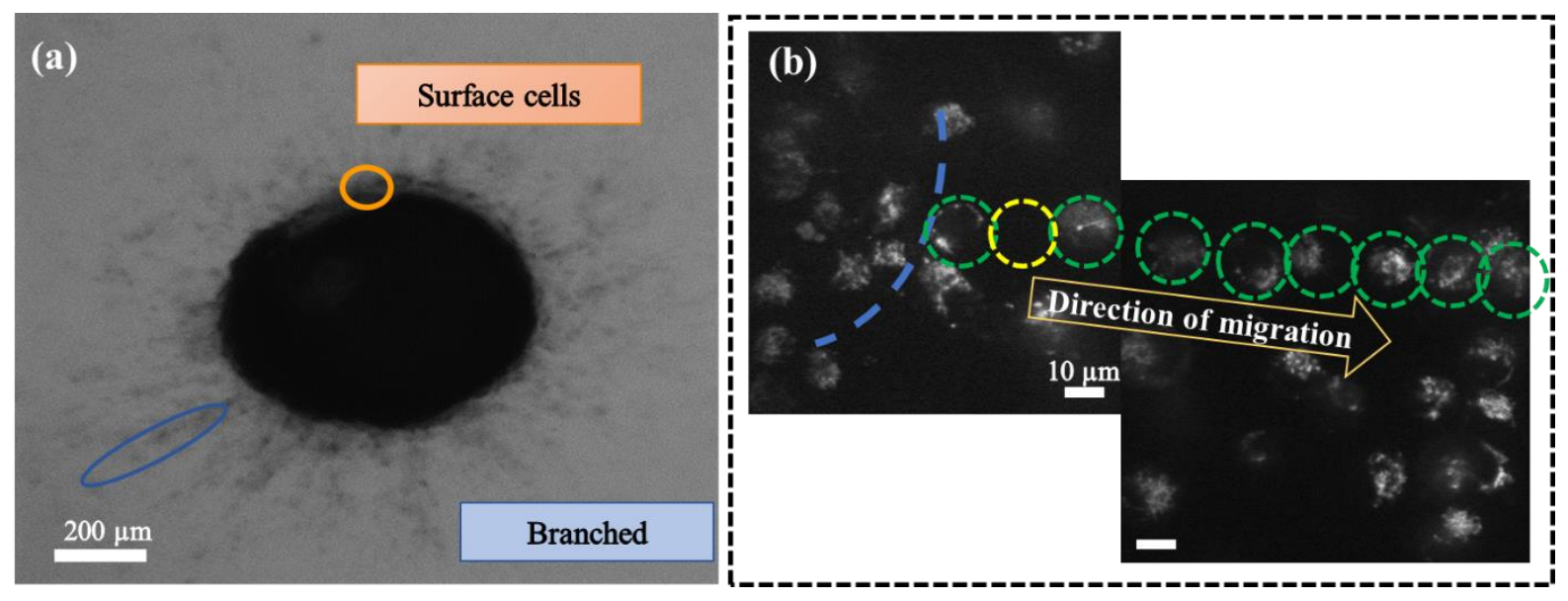

Figure 1: Illustration of detaching (surface) and migrated (branched) cells as (a) bright-field image (5x magnification) and $(b)$ mitochondrial fluorescent image (63x magnification). The blue dashed line indicates the spheroid border, green dashed circles indicate the approximate diameter of cells migrating away from the spheroid in a branch, and the yellow dashed circle indicates a cell out of focus.

\subsection{Effect of detachment and migration: Migrated cells are more deformable than detaching cells}

The effect of detachment and migration of cells on mitochondrial fluctuations and cell deformability was assessed in 2 and $4 \mathrm{mg} / \mathrm{ml}$ collagen (Figure 2). The MSD of 0dc, 4dc, and 6dc cells in 2 and $4 \mathrm{mg} / \mathrm{ml}$ collagen increased with increasing delay time. To determine the viscoelastic properties of cells as the distance from the spheroid increased, MSD and $\alpha$ data were evaluated and reported below for short delay times of $\tau=0.05 \mathrm{~s}$ and $2 \mathrm{~s}$, respectively.

In $2 \mathrm{mg} / \mathrm{ml}$ collagen matrices, mitochondrial fluctuation was larger and intracellular fluidity was smaller for cells at the spheroid surface, i.e. $\mathrm{d}_{\mathrm{m}}=0 \mathrm{dc}_{\mathrm{c}}$, than for cells detached and invaded the environment (Figure $2 \mathrm{a}$ and $\mathrm{b}$ ). The MSD in $0 \mathrm{~d}_{\mathrm{C}}$ cells was $0.016 \pm 0.004 \mu^{2}$ compared to 
$4 \mathrm{~d}_{\mathrm{C}}$ cells with $0.012 \pm 0.002 \mu \mathrm{m}^{2}(p=.012)$ and $6 \mathrm{~d}_{\mathrm{C}}$ cells with $0.012 \pm 0.003 \mu \mathrm{m}^{2}(p=.010)$. The MSD of $4 \mathrm{dc}$ and $6 \mathrm{dc}$ were similar $(p=.946)$. The intracellular fluidity $\alpha$ of $0 \mathrm{~d}_{\mathrm{C}}$ cells $(0.311$ $\pm 0.298)$ was lower than that of $4 \mathrm{~d}_{\mathrm{C}}(0.815 \pm 0.243, p<.001)$ and $6 \mathrm{~d}_{\mathrm{C}}$ cells $(0.664 \pm 0.159, p$ $=.003)$, and $\alpha$ was larger for $4 \mathrm{~d}_{\mathrm{C}}$ cells than for $6 \mathrm{~d}_{\mathrm{C}}$ cells, although non-significant $(p=.173)$. The mitochondrial motion was strongly sub-diffusive in 0dc cells, closely diffusive in $4 \mathrm{~d}_{\mathrm{C}}$ cells, and weakly sub-diffusive in $6 \mathrm{~d}_{\mathrm{C}}$ cells.

In the $4 \mathrm{mg} / \mathrm{ml}$ collagen environment, the MSD of the $0 \mathrm{dc}$ cells of $0.014 \pm 0.005 \mu \mathrm{m}^{2}$ was slightly larger than for $4 \mathrm{~d}_{\mathrm{C}}\left(0.012 \pm 0.004 \mu \mathrm{m}^{2}\right)$ and $6 \mathrm{~d}_{\mathrm{C}}$ cells $\left(0.011 \pm 0.004 \mu \mathrm{m}^{2}\right)$ (Figure $\left.2 \mathrm{c}\right)$. These differences were, however, not significant $(p=.436)$. The observations for intracellular fluidity $\alpha$ were similar to those in the $2 \mathrm{mg} / \mathrm{ml}$ collagen, although differences were not significant $(p=.151)$. The $0 \mathrm{~d}_{\mathrm{C}}$ cells exhibited lower fluidity $(0.487 \pm 0.284)$ than the $4 \mathrm{~d}_{\mathrm{C}}(0.734$ $\pm 0.220)$ and $6 \mathrm{~d}_{\mathrm{C}}$ cells $(0.659 \pm 0.349)$. The fluidity values indicated that the migrated $4 \mathrm{~d}_{\mathrm{C}}$ and $6 d_{C}$ cells displayed weaker sub-diffusive motion than the $0 d_{C}$ cells at the spheroid surface (Figure 2d).
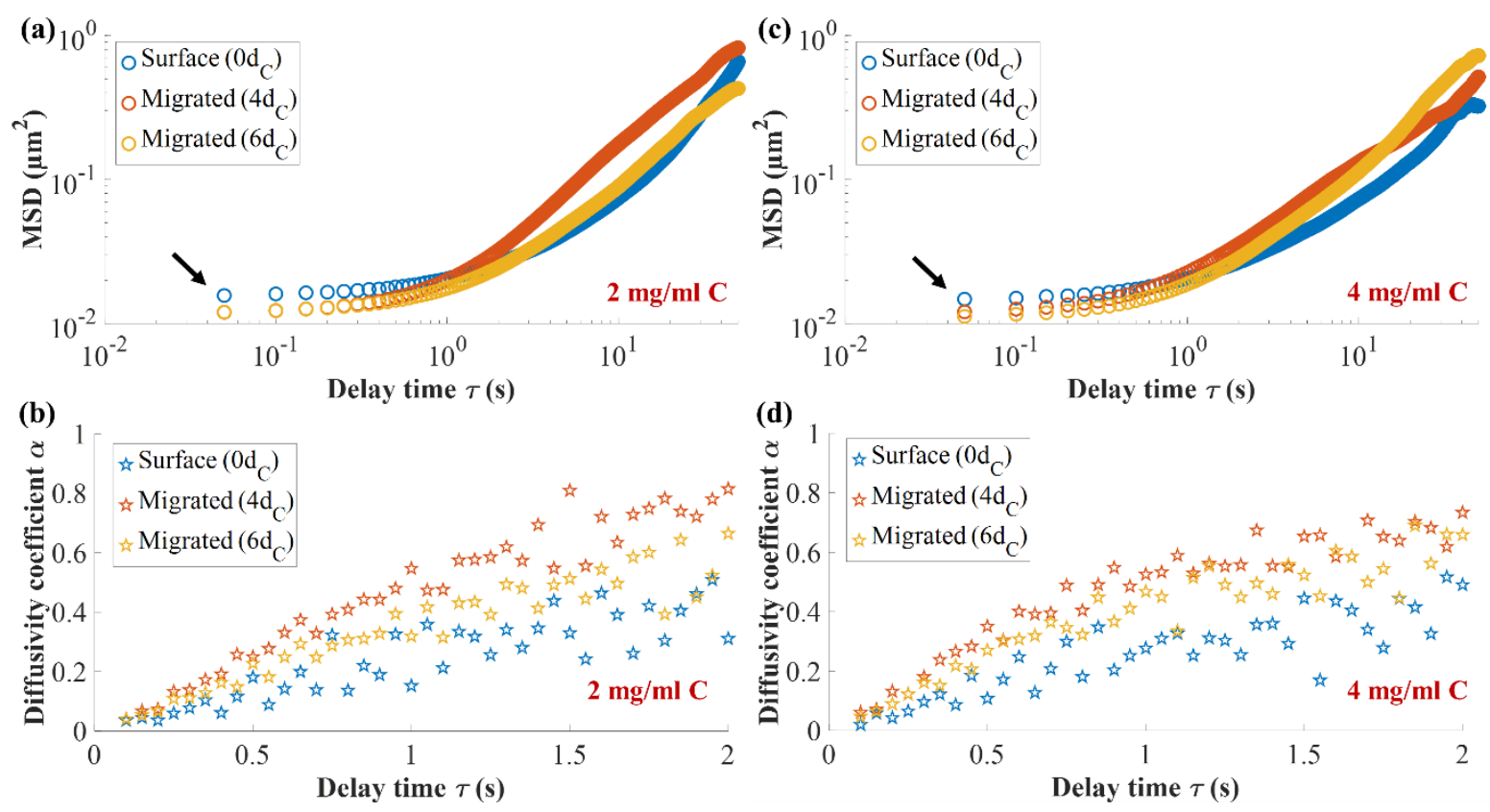

Figure 2: Intracellular fluctuations from spheroids $(n=2)$ in 2 and $4 \mathrm{mg} / \mathrm{ml}$ collagen gels. $M S D$ and diffusivity coefficient $\alpha$ versus delay time of cells in $2 \mathrm{mg} / \mathrm{ml}$ collagen $(a, b)$ and in 4 $\mathrm{mg} / \mathrm{ml}$ collagen $(c, d)$. Error bars omitted for clarity. Arrows indicate MSD at short delay times of $\tau=0.05 \mathrm{~s}$. Trends of MSD and $\alpha$ of cells were similar in 2 and $4 \mathrm{mg} / \mathrm{ml}$ collagen. Mitochondrial fluctuations of Odc were larger than migrated $4 d_{c}$ and $6 d_{c}$ cells. Odc cells exhibited the largest cell stiffness, followed by $6 d_{c}$ and then $4 d_{c}$ cells. 


\subsection{Matrix rigidity affects cell stiffness during detachment but not during subsequent migration}

The effect of changes in matrix rigidity on mitochondrial fluctuations and cell deformability was assessed for varying migration distances from the tumour spheroids.

The increased concentration and rigidity of the collagen matrix did not affect the mitochondrial fluctuations of the cells. The MSD of $0 \mathrm{dc}_{\mathrm{c}} 4 \mathrm{dc}$ and $6 \mathrm{dc}_{\mathrm{c}}$ cells in $4 \mathrm{mg} / \mathrm{ml}$ was similar to that in $2 \mathrm{mg} / \mathrm{ml}$ collagen $(p=.290, p=.773$ and $p=.426$, respectively) (Figure 3a).

An increase, although not significant, in intracellular fluidity $\alpha$ with increased collagen concentration was observed for the $0 \mathrm{~d}_{\mathrm{C}}$ cells at the spheroid surface $(p=.182)$ but not for the migrated $4 \mathrm{~d}_{\mathrm{C}}(p=.444)$ and $6 \mathrm{~d}_{\mathrm{C}}$ cells $(p=.964)$ (Figure 3b).

(a)

$\square 2 \mathrm{mg} / \mathrm{ml} \mathrm{C} \quad 4 \mathrm{mg} / \mathrm{ml} \mathrm{C}$

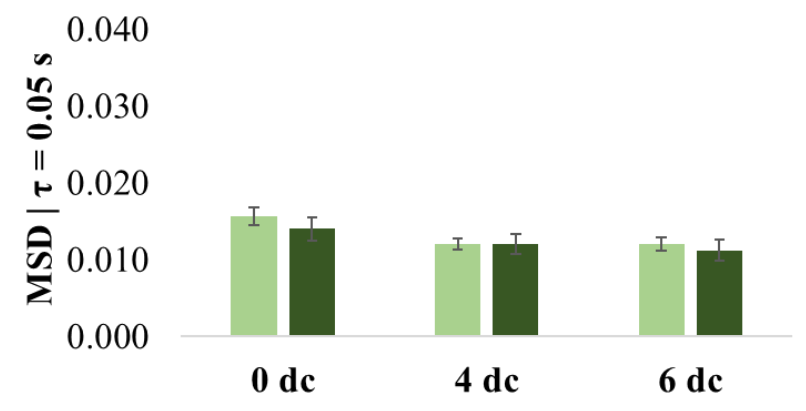

(b)

$\square 2 \mathrm{mg} / \mathrm{ml} \mathrm{C} \quad 4 \mathrm{mg} / \mathrm{ml} \mathrm{C}$

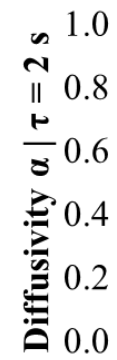

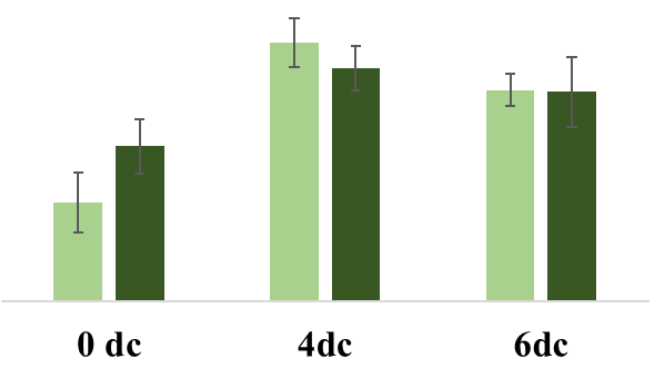

Figure 3: Comparison of the MSD and fluidity of cells at the spheroid surface (OdC) and after migration of a distance of $4 d_{C}$ and $6 d_{C}$ from the spheroid surface in 2 and $4 \mathrm{mg} / \mathrm{ml}$ collagen matrices $(C)$ ( $d_{C}$ indicates cell diameter). Increased matrix rigidity increased the fluidity of $0 d_{C}$ cells but did not affect the fluidity of $4 d_{c}$ and $6 d_{c}$ cells. a) The MSD of Odc cells was $0.016 \pm$ $0.001 \mu^{2}$ (in $2 \mathrm{mg} / \mathrm{ml} \mathrm{C}$ ) and $0.014 \pm 0.002 \mu^{2}$ (in $4 \mathrm{mg} / \mathrm{ml} \mathrm{C}$ ), of 4 dC cells was $0.012 \pm 0.001$ $\mu \mathrm{m}^{2}$ (in $2 \mathrm{mg} / \mathrm{ml} \mathrm{C}$ ) and $0.012 \pm 0.001 \mu^{2}$ (in $4 \mathrm{mg} / \mathrm{ml} \mathrm{C}$ ), and of $6 \mathrm{~d}_{C}$ cells was $0.012 \pm 0.001$ $\mu^{2}$ (in $2 \mathrm{mg} / \mathrm{ml} \mathrm{C}$ ) and $0.011 \pm 0.001 \mu^{2}$ (in $4 \mathrm{mg} / \mathrm{ml} \mathrm{C}$ ). b) The diffusivity coefficient $\alpha$ of Odc cells was $0.311 \pm 0.094$ (in $2 \mathrm{mg} / \mathrm{ml} \mathrm{C}$ ) and $0.487 \pm 0.086$ (in $4 \mathrm{mg} / \mathrm{ml} \mathrm{C}$ ), of 4dc cells was $0.815 \pm 0.077$ (in $2 \mathrm{mg} / \mathrm{ml} \mathrm{C}$ ) and $0.734 \pm 0.069$ (in $4 \mathrm{mg} / \mathrm{ml} \mathrm{C}$ ), and of 6dc cells was $0.664 \pm$ 0.050 (in $2 \mathrm{mg} / \mathrm{ml} \mathrm{C}$ ) and $0.659 \pm 0.110$ (in $4 \mathrm{mg} / \mathrm{ml} \mathrm{C}$ ). All differences were non-significant. Values are mean \pm SEM, error bars are SEM. 


\section{Discussion}

In the present study, metastatic breast adenocarcinoma cells, MDA-MB-231, were embedded as tumour spheroids in collagen gels of two different concentrations ( 2 and $4 \mathrm{mg} / \mathrm{ml}$ collagen) to investigate the mechanical properties of the cancer cells associated with of tumour-cell detachment and migration in physiologically relevant 3D environments. Mitochondrial-based particle tracking microrheology was utilised to probe intracellular fluctuations. Cells were distinguished between cells attached to the spheroid, i.e. before tumour-cell detachment, and migrated cells that have employed the necessary processes to detach and gain enhanced migratory properties for cell dissemination away from the tumour spheroid. Cells were denoted according to the distance migrated from the spheroid in terms of cell diameter $\left(\mathrm{dc}_{\mathrm{c}}\right)$, where $0 \mathrm{~d}_{\mathrm{c}}$, $4 \mathrm{dc}$ and $6 \mathrm{dc}_{\mathrm{c}}$ represented no, medium and high migration, respectively.

This study extends work on the microrheological characterisation of breast cancer cells in 3D environments. MDA-MB-231 cells were used since their mechanics has been extensively studied as single cells in both 2D and 3D environments (Baker et al. 2009, Mak et al. 2014), and with and without drug treatment (Kim et al. 2018, Wullkopf et al. 2018). However, the intracellular mechanics that aid cells in detaching from the tumour and invading the surrounding matrix is not well studied. Here, the microrheology of cells during physiological relevant processes such as tumour detachment and directed migration were characterised in 3D environments.

The findings of this study indicate that cells are more solid-like before tumour detachment than after detachment and migration into the surrounding matrix. The cells at the spheroid surface (i.e. $0 \mathrm{~d}_{\mathrm{C}}$ ) displayed a lower fluidity $\alpha$, alluding to increased cell stiffness, than migrated $4 \mathrm{~d}_{\mathrm{C}}$ and $6 \mathrm{dc}_{\mathrm{c}}$ cells in both 2 and $4 \mathrm{mg} / \mathrm{ml}$ collagen concentrations. In the context of migration, studies have shown that increased migratory potentials were inversely related to increased cell stiffness, irrespective of whether different grades of cancers from the same cancer type or the same tumour specimen were used (Swaminathan et al. 2011, Xu et al. 2012).

(Swaminathan et al. 2011, Xu et al. 2012) used cell spheroids of a highly invasive breast cancer cell line $4 \mathrm{~T} 1$ and pancreatic cancer cell line $\mathrm{KP}^{\mathrm{R} 172} \mathrm{HC}$ to measure the cell stiffness at the centre of the spheroid and in the stalk and the tip of branches of invading cells in compliant and rigid collagen matrices. Here, the cells in the spheroid centre, branch stalk, and branch tip represented no migration, medium migration, and large migration, respectively. Irrespective of 
the rigidity of the collagen matrix, the stiffness of tip cells that had migrated furthest was lower than that of cells in the spheroid centre (Wullkopf et al. 2018). These results support our findings. However, it is important to mention that the cell stiffness of $4 \mathrm{~d}_{\mathrm{C}}$ cells that have migrated medium distances was lower than the stiffness of $6 \mathrm{~d}_{\mathrm{C}}$ cells that have migrated large distances in 3D matrices of different rigidity. In particularly, the diffusivity $\alpha$ of cells increased from $0 \mathrm{~d}_{\mathrm{C}}$ to $4 \mathrm{~d}_{\mathrm{C}}$ cells and decreased from $4 \mathrm{~d}_{\mathrm{C}}$ to $6 \mathrm{~d}_{\mathrm{C}}$ cells in $2 \mathrm{mg} / \mathrm{ml}$ and $4 \mathrm{mg} / \mathrm{ml}$ collagen matrices.

The $0 \mathrm{~d}_{\mathrm{C}}$ cells were connected to the spheroid through cell-cell adhesion, whereas $4 \mathrm{~d}_{\mathrm{C}}$ and $6 \mathrm{~d}_{\mathrm{C}}$ cells detached and migrated away from the spheroid. Migrated cells are, therefore, less mechanically influenced by the tumour and instead adapt to the rigidity of the matrix. Interestingly, the cell stiffness at $6 \mathrm{~d}_{\mathrm{C}}$ distance from the spheroid was higher than that of $4 \mathrm{~d}_{\mathrm{C}}$ cells. Reports on the migration of cells in 3D environments show that MDA-MB-231 cells require actomyosin-based contractility to invade the matrix despite their spherical morphology (Poincloux et al. 2011). It is therefore proposed that the increased migration of 6dc cells compared to $4 \mathrm{~d} \mathrm{c}$ cells requires increased actomyosin contractility, and hence increased cell stiffness. Furthermore, mitochondrial fluctuations in migrated $4 \mathrm{~d}_{\mathrm{C}}$ and $6 \mathrm{~d}_{\mathrm{C}}$ cells neared or entered the diffusive regime much earlier than in $0 \mathrm{~d}_{\mathrm{C}}$ cells, indicating heightened motor activity to contract the cytoskeleton in preparation for migration and invasion into the gel (Guo et al. 2014).

In the lower collagen concentration $(2 \mathrm{mg} / \mathrm{ml})$, the motion of the mitochondrial particles of $0 \mathrm{~d}_{\mathrm{C}}, 4 \mathrm{dc}_{\mathrm{c}}$ and $6 \mathrm{~d}_{\mathrm{c}}$ cells was strongly sub-diffusive $(\alpha<0.3)$, diffusive $(\alpha=1.0)$ and weakly subdiffusive $(0.7<\alpha<1.0)$, respectively. In the higher collagen concentration $(4 \mathrm{mg} / \mathrm{ml})$, mitochondria of $0 \mathrm{~d}_{\mathrm{C}}$ were sub-diffusive, whereas mitochondria of $4 \mathrm{~d}_{\mathrm{C}}$ and $6 \mathrm{~d}_{\mathrm{C}}$ cells were weakly sub-diffusive. Importantly, these observations indicate that weakly sub-diffusive to diffusive behaviour is characteristic of cells that migrated away from their tumour spheroid.

The migrating cells exhibited amoeboid motility and moved in a straight path away from the spheroid. Amoeboid migration strongly is driven by increased myosin II-mediated contractility (Poincloux et al. 2011). Hence it is suggested that the diffusive mitochondrial motion we observed in migrating cells is based on increased myosin II-mediated contractility.

Increased matrix rigidity played a role in decreasing the cell stiffness of cells at the spheroid but had no impact on the stiffness of migrated cells. The intracellular fluidity $\alpha$ of $0 \mathrm{~d}_{\mathrm{C}}$ cells was lower in $2 \mathrm{mg} / \mathrm{ml}$ than in $4 \mathrm{mg} / \mathrm{ml}$ collagen, whereas $\alpha$ of $4 \mathrm{~d}_{\mathrm{C}}$ and $6 \mathrm{~d}_{\mathrm{C}}$ cells were similar 
in 2 and $4 \mathrm{mg} / \mathrm{ml}$ collagen matrices. Increased matrix rigidity has been reported to increase intracellular activity and decrease cell stiffness of isolated cells in 3D environments (Baker $e t$ al. 2009, Butcher et al. 2009). The fluidity of $0 \mathrm{~d}_{\mathrm{C}}$ cells at the spheroid surface is consistent with these reports. For migrated cells, the similar fluidity of $4 \mathrm{~d}_{\mathrm{C}}$ and $6 \mathrm{~d}_{\mathrm{C}}$ cells in soft and stiff matrices are consistent with the results of Wullkopf et al. (2018). The authors showed that the stiffness of invasive breast cancer $4 \mathrm{~T} 1$ and pancreatic cancer $\mathrm{KP}^{\mathrm{R} 172} \mathrm{HC}$ cells on the stalk and tip of invading branches of spheroids were similar in collagen matrices of high and low rigidity (Wullkopf et al. 2018). Combined with the effect of migrated distance, this finding suggests that cells acquire maximum deformability during migration irrespective of the rigidity of the matrix. It is known that cells can remodel their environment and that the secretion of matrix metalloproteases (MMPs) increase with cancer progression (Harjanto et al. 2011). It is therefore proposed that $4 \mathrm{~d}_{\mathrm{C}}$ and $6 \mathrm{~d}_{\mathrm{C}}$ cells degrade dense collagen matrices by secreting MMPs to facilitate migration.

The present study focused solely on cell detachment and migration from breast tumour spheroids. Future work should entail repeating the current study with a different cancer disease, such as melanoma, to provide a more comprehensive understanding of the adjustment of intracellular mechanics of cells during cell detachment and invasion.

Conventional spheroid invasion assays determine the signalling pathways involved in the invasion process (Naber et al. 2012, Wiercinska et al. 2011). Complementing these studies with PTM experiments would provide more powerful tools to understand how cancer cells regulate mechanical and biochemical cues to metastasise. For example, transforming growth factor $\beta$ (TGF $\beta$ ) signalling is commonly studied in spheroid invasion assays, and reports have shown that TGF $\beta$ plays a vital role in stimulating invasion and metastasis in advanced breast cancer (Wiercinska et al. 2011). Expansion of the present study could study the effects of TGF $\beta$ on the intracellular stiffness of metastatic breast cancer cells during tumour detachment and invasion.

\section{Conclusion}

It was shown that mitochondrial particle tracking microrheology could detect changes in cell stiffness of metastatic breast cancer cells as cells detached and migrated away from their spheroids in soft and stiff collagen matrices. Consistent with several reports (Guck et al. 2005, Remmerbach et al. 2009), this study suggests that decreased cell stiffness mediates the escape 
of cells from the initial metastatic niche. Based on the difference in cell stiffness between $4 \mathrm{~d}_{\mathrm{C}}$ and $6 \mathrm{~d}_{\mathrm{C}}$ cells, it is proposed that upon escaping the initial metastatic niche, cells require increased actomyosin contractility to migrate. The findings of this study provide insights into the collective effects of enhanced migratory conditions and increased matrix rigidity on the mechanical properties of cells. These results are valuable and can be implemented in the development of therapeutics to target cells not only migrating in 3D but more importantly, cells at the initial tumour site, thereby preventing metastatic spread.

\section{References}

Baker EL, Bonnecaze RT, Zaman MH. Extracellular matrix stiffness and architecture govern intracellular rheology in cancer. Biophys J 2009, 97(4): 1013-21.

Baker EL, Lu J, Yu D, Bonnecaze RT, Zaman MH. Cancer cell stiffness: Integrated roles of three-dimensional matrix stiffness and transforming potential. Biophys J 2010, 99(7): 204857.

Butcher DT, Alliston T, Weaver VM. A tense situation: Forcing tumour progression. Nat Rev Cancer 2009, 9(2): 108-22.

Close DA, Camarco DP, Shan F, Kochanek SJ, Johnston PA. The generation of threedimensional head and neck cancer models for drug discovery in 384-well ultra-low attachment microplates. Methods Mol Biol 2018, 1683: 355-69.

Costa EC, Moreira AF, De Melo-Diogo D, Gaspar VM, Carvalho MP, Correia IJ. 3D tumor spheroids: An overview on the tools and techniques used for their analysis. Biotechnol Adv 2016, 34(8): 1427-41.

Cui X, Hartanto Y, Zhang H. Advances in multicellular spheroids formation. J R Soc Interface 2017, 14(127).

Fennema E, Rivron N, Rouwkema J, Van Blitterswijk C, De Boer J. Spheroid culture as a tool for creating $3 D$ complex tissues. Trends Biotechnol 2013, 31(2): 108-15.

Gal N, Weihs D. Intracellular mechanics and activity of breast cancer cells correlate with metastatic potential. Cell Biochem Biophys 2012, 63(3): 199-209.

Geiger F, Rudiger D, Zahler S, Engelke H. Fiber stiffness, pore size and adhesion control migratory phenotype of MDA-MB-231 cells in collagen gels. PLoS One 2019, 14(11): $\mathrm{e} 0225215$.

Guck J, Schinkinger S, Lincoln B, Wottawah F, Ebert S, Romeyke M, et al. Optical deformability as an inherent cell marker for testing malignant transformation and metastatic competence. Biophys J 2005, 88(5): 3689-98. 
Guo M, Ehrlicher AJ, Jensen MH, Renz M, Moore JR, Goldman RD, et al. Probing the stochastic, motor-driven properties of the cytoplasm using force spectrum microscopy. Cell 2014, 158(4): 822-32.

Harjanto D, Maffei JS, Zaman MH. Quantitative analysis of the effect of cancer invasiveness and collagen concentration on 3D matrix remodeling. PLoS ONE 2011, 6(9): e24891.

Kim JE, Reynolds DS, Zaman MH, Mak M. Characterization of the mechanical properties of cancer cells in $3 D$ matrices in response to collagen concentration and cytoskeletal inhibitors. Integr Biol (Camb) 2018, 10(4): 232-41.

Mak M, Kamm RD, Zaman MH. Impact of dimensionality and network disruption on microrheology of cancer cells in $3 D$ environments. PLoS Comput Biol 2014, 10(11): e1003959.

Metzger W, Sossong D, Bachle A, Putz N, Wennemuth G, Pohlemann T, Oberringer M. The liquid overlay technique is the key to formation of co-culture spheroids consisting of primary osteoblasts, fibroblasts and endothelial cells. Cytotherapy 2011, 13(8): 1000-12.

Mitrossilis D, Fouchard J, Pereira D, Postic F, Richert A, Saint-Jean M, Asnacios A. Real-time single-cell response to stiffness. Proc Natl Acad Sci U S A 2010, 107(38): 16518-23.

Naber HP, Wiercinska E, Pardali E, Van Laar T, Nirmala E, Sundqvist A, et al. Bmp-7 inhibits TGF-beta-induced invasion of breast cancer cells through inhibition of integrin beta(3) expression. Cell Oncol (Dordr) 2012, 35(1): 19-28.

Omidvar R, Tafazzoli-Shadpour M, Shokrgozar MA, Rostami M. Atomic force microscopebased single cell force spectroscopy of breast cancer cell lines: An approach for evaluating cellular invasion. J Biomech 2014, 47(13): 3373-9.

Poincloux R, Collin O, Lizarraga F, Romao M, Debray M, Piel M, Chavrier P. Contractility of the cell rear drives invasion of breast tumor cells in 3D matrigel. Proc Natl Acad Sci U S A 2011, 108(5): 1943-8.

Remmerbach TW, Wottawah F, Dietrich J, Lincoln B, Wittekind C, Guck J. Oral cancer diagnosis by mechanical phenotyping. Cancer Res 2009, 69(5): 1728-32.

Reynolds DS, Tevis KM, Blessing WA, Colson YL, Zaman MH, Grinstaff MW. Breast cancer spheroids reveal a differential cancer stem cell response to chemotherapeutic treatment. Sci Rep 2017, 7(1): 10382.

Schindelin J, Arganda-Carreras I, Frise E, Kaynig V, Longair M, Pietzsch T, et al. Fiji: An open-source platform for biological-image analysis. Nat Methods 2012, 9(7): 676-82.

Swaminathan V, Mythreye K, O'brien ET, Berchuck A, Blobe GC, Superfine R. Mechanical stiffness grades metastatic potential in patient tumor cells and in cancer cell lines. Cancer Res 2011, 71(15): 5075-80.

Tarantino N, Tinevez JY, Crowell EF, Boisson B, Henriques R, Mhlanga M, et al. TNF and IL-1 exhibit distinct ubiquitin requirements for inducing NEMO-IKK supramolecular structures. J Cell Biol 2014, 204(2): 231-45. 
Tinevez JY, Perry N, Schindelin J, Hoopes GM, Reynolds GD, Laplantine E, et al. TrackMate: An open and extensible platform for single-particle tracking. Methods 2017, 115: 80-90.

Wiercinska E, Naber HP, Pardali E, Van Der Pluijm G, Van Dam H, Ten Dijke P. The TGFbeta/Smad pathway induces breast cancer cell invasion through the up-regulation of matrix metalloproteinase 2 and 9 in a spheroid invasion model system. Breast Cancer Res Treat 2011, 128(3): 657-66.

Wullkopf L, West AV, Leijnse N, Cox TR, Madsen CD, Oddershede LB, Erler JT. Cancer cells' ability to mechanically adjust to extracellular matrix stiffness correlates with their invasive potential. Mol Biol Cell 2018, 29(20): 2378-85.

Xu W, Mezencev R, Kim B, Wang L, Mcdonald J, Sulchek T. Cell stiffness is a biomarker of the metastatic potential of ovarian cancer cells. PLoS One 2012, 7(10): e46609. 